\title{
Cardiorenal Syndrome: The Clinical Cardiologists' Perspective
}

\author{
Eric J. Chan Kevin C. Dellsperger \\ Division of Cardiovascular Medicine, Department of Internal Medicine, University of Missouri, \\ Columbia, Mo., USA
}

\section{Key Words}

Cardiorenal syndrome $\cdot$ Chronic kidney disease $\cdot$ Coronary artery disease $\cdot$ Heart failure $\cdot$ Metabolic syndrome

\begin{abstract}
The term cardiorenal syndrome has evolved over the years. The understanding of the interactions between these two organ systems has led to better recognition and treatment strategies. As cardiovascular mortality is high in individuals with renal dysfunction, it is imperative to understand the pathophysiology behind the disease process. This knowledge may better serve these patients with this syndrome and improve their outcomes. In this review, we examine the key issues of the cardiorenal syndrome from a cardiologist's perspective.
\end{abstract}

Copyright $\odot 2011$ S. Karger AG, Basel

\section{Introduction}

The term 'cardiorenal syndrome', a relatively new term, refers to the interactivity between the cardiovascular and renal systems. Over the past decade, we have gained a better understanding of the relationship between these two organ systems. The initial definition of worsening renal function secondary to poor left ventricular function has advanced to a more current and sophisticated classification which attempts to relate the pathophysiology of cardiac and renal dysfunction and their interplay (table 1). Regardless of the precise etiology of cardiac and renal disease, these interactive disease processes lead to increased morbidity and mortality. This review focuses on the cardiologist's perspective into the cardiorenal syndrome and the important pathophysiological mechanisms responsible for the decline and worsening of both cardiac and renal function. 
Table 1. Cardiorenal syndrome classification

\begin{tabular}{ll}
\hline Types & Description \\
\hline CRS type 1 & Acute cardiac decompensation leading to kidney injury \\
CRS type 2 & Chronic heart failure leading to worsening renal function \\
CRS type 3 & Acute kidney injury leading to cardiac dysfunction \\
CRS type 4 & Chronic kidney disease leading to heart failure \\
CRS type 5 & Systemic conditions leading to both cardiac and renal dysfunction \\
\hline
\end{tabular}

CRS = Cardiorenal syndrome (see also Editorial by Ronco and Ronco et al. [2]).

\section{Defining the Cardiorenal Syndrome}

Several decades ago, Dr. Guyton described interactions between the heart and kidney dysfunction that would produce feedback loops and worsen the function of both organs. While not coined the cardiorenal syndrome, our current understanding represents an evolution of Guyton's description [1]. To assist in the definition, a classification of the cardiorenal syndrome was proposed, which consists of five subtypes that are divided by the initial organ of dysfunction and the chronicity of the disease [2]. Using this model as an organized outline helps focus our understanding of the pathophysiology of the cardiorenal syndrome and the clinical issues that arise.

\section{Cardiorenal Syndrome Types}

\section{Type 1: The Acutely Decompensated Heart}

Heart failure accounts for over 1 million discharges every year in the United States [3]. The magnitude of this disorder exemplifies the difficult task clinicians face in treating heart failure and its associated complications. A major complication and comorbidity of heart failure is acute or chronic renal disease (CRD). The Acute Decompensated Heart Failure National Registry (ADHERE) examined $>105,000$ patients with admission for acute decompensated heart failure. CRD was reported in $30 \%$ of these cases and $21 \%$ had serum creatinine (SCr) levels $>2.0 \mathrm{mg} / \mathrm{dl}$ [4]. The registry also found that the best single predictor of inpatient mortality was high levels of blood urea nitrogen $(>43 \mathrm{mg} / \mathrm{dl})$ on admission in addition to high levels of SCr $(>2.75 \mathrm{mg} / \mathrm{dl})$ [5]. The results of the ADHERE registry show that renal dysfunction is an important independent risk factor for mortality in heart failure patients.

According to the American Heart Association, an estimated 785,000 Americans will have a new ischemic coronary event, and 470,000 will have a recurrent ischemic coronary attack in the year 2010 [3]. These numbers translate to an acute coronary syndrome approximately every $25 \mathrm{~s}$. Ischemic heart disease is the leading cause of acutely decompensated cardiac function. The effects of poor perfusion secondary to low cardiac output can cause hypoperfusion of the kidneys leading to renal dysfunction. The renin-angiotensin-aldosterone system (RAAS) is activated by hypoperfusion of the kidney and this results in an increase in angiotensin II (Ang II) and aldosterone. Ang II binds to two receptor types, AT1 and AT2. Ang II binding to AT1 receptors leads to vasoconstriction and aldosterone secretion. Aldosterone promotes maladaptive reabsorption of sodium in the distal tubules leading to water retention and worsening pulmonary vascular congestion [6]. The mechanism of acute kidney injury (AKI) in this setting is partly attributable to RAAS activation as well. A by-product of increased Ang II levels is endothelin-1. Endothelin-1 is a potent vasoconstrictor that 


\section{CardioRenal \\ Medicine}

\begin{tabular}{l|l}
\hline \multicolumn{2}{l}{ Cardiorenal Med 2011;1:13-22 } \\
\hline DOI: 10.1159/000322820 & $\begin{array}{l}\text { @ 2011 S. Karger AG, Basel } \\
\text { www.karger.com/crm }\end{array}$ \\
Published online: January 17, 2011 &
\end{tabular}

Chan et al.: Clinical Aspects of the Cardiorenal Syndrome

leads to renal arteriolar constriction resulting in renal ischemia [7]. This induces a cycle of vasoconstriction and inflammatory responses that ultimately results in additional renal injury. Blockade of endothelin receptors in animal models has shown to improve glomerular filtration rate (GFR) and renal blood flow [8].

Contrast-induced nephropathy (CIN) is another important clinical complication of an acute coronary syndrome as a result of revascularization. The exact definition of CIN differs, but most characterize it as an increase in SCr from 0.5 to $1.0 \mathrm{mg} / \mathrm{dl}$ or an increase from baseline by $25-50 \%$ within $72 \mathrm{~h}$ following contrast administration [9]. The variable definition leads to a broad range of reported incidence rates of CIN anywhere from $0 \%$ to as much as $50 \%$ in higher-risk individuals [10]. Whether the type of contrast medium used affects CIN has been a topic of great debate.

A large, randomized, clinical trial compared ionic (diatrizoate meglumine/sodium) and nonionic (iohexol) contrast media. A total of 1,196 patients were enrolled and followed for at least $48 \mathrm{~h}$ after catheterization. The results showed that in the iohexol group 3.2\% of the patients had an increase in SCr $>1.0 \mathrm{mg} / \mathrm{dl}$ compared to $7.1 \%$ in the diatrizoate group [11]. The patients who developed nephrotoxicity were mainly those who had baseline renal dysfunction, regardless of whether they had diabetes mellitus. Therefore, this study demonstrated that using low-osmolar nonionic contrast media may decrease the incidence of renal dysfunction. Iodixanol was compared with iohexol in a double-blind, randomized, prospective study of 129 patients. Results showed that the mean creatinine level increased significantly more in the iohexol group compared to the iodixanol group [12]. While the type of radiocontrast medium used has evolved over the years, the key is still identifying patients at risk for CIN prior to a contrast procedure such as cardiac catheterization with coronary angiography. A risk score was created to predict CIN after percutaneous coronary intervention (PCI). A total of 8,357 patients were enrolled. The results showed that eight variables, including hypotension, use of an intra-aortic balloon pump, congestive heart failure, chronic kidney disease (CKD), diabetes, age $>75$ years, anemia, and contrast volume, were found to be independent predictors of CIN [13]. These variables, which are easily obtainable from an admission evaluation, can help clinicians risk stratify patients.

Identifying patients with acute coronary syndrome and ischemia is crucial, especially in those presenting with cardiogenic shock. The overall prognosis of cardiogenic shock in the setting of myocardial infarction alone is associated with poor outcomes, with mortality rates of almost $50 \%[14,15]$. In this setting, AKI is a serious complication, with the incidence of AKI in ST-elevation myocardial infarction being around 50\% [14]. In other studies, AKI has been found to be a strong independent predictor of mortality, with in-hospital mortality rates as high as $87 \%$ [15].

\section{Type 2: Chronic Heart Disease Which Results in Kidney Disease}

The second subtype of cardiorenal syndrome is most often associated with chronic heart failure leading to renal dysfunction [2]. The presumed pathophysiology is chronic poor forward flow leading to renal hypoperfusion. Poor cardiac output leads to RAAS activation and eventual fibrosis and negative myocardial remodeling. Though this is the prevailing concept, recent data do not support this as the only explanation. The Evaluation Study of Congestive Heart Failure and Pulmonary Artery Catheterization Effectiveness (ESCAPE) randomized 433 heart failure patients to receive therapy guided by a pulmonary artery catheter or clinical assessment alone [16]. The median baseline SCr was $1.5 \mathrm{mg} / \mathrm{dl}$ and median GFR was 71.4 $\mathrm{ml} / \mathrm{min}$. The results in the 193 patients treated with a pulmonary artery catheter showed that there was no correlation between SCr or GFR and pulmonary capillary wedge pressure, cardiac index or systemic vascular resistance. Furthermore, improvement in the cardiac index $\left(1.9-2.4 \mathrm{l} / \mathrm{min} / \mathrm{m}^{2}\right)$ did not improve renal function [17]. 


\section{CardioRenal \\ Medicine}

\begin{tabular}{l|l}
\hline \multicolumn{2}{l}{ Cardiorenal Med 2011;1:13-22 } \\
\hline DOI: 10.1159/000322820 & $\begin{array}{l}\text { @ 2011 S. Karger AG, Basel } \\
\text { www.karger.com/crm }\end{array}$ \\
Published online: January 17, 2011 &
\end{tabular}

Chan et al.: Clinical Aspects of the Cardiorenal Syndrome

A significant correlation between right atrial pressure and baseline SCr and GFR was observed suggesting a role for systemic venous congestion in the development of renal dysfunction [16]. For example, in 145 patients admitted with acute decompensated heart failure, patients with higher baseline central venous pressure had a higher risk of worsening renal function. When treated to a central venous pressure of $<8 \mathrm{~mm} \mathrm{Hg}$, the incidence of renal dysfunction was decreased during inpatient hospitalization. The overall change in the baseline cardiac index did not affect GFR during hospitalization, similar to ESCAPE findings [18]. These observations suggest that worsening forward flow in chronic heart failure may not be the only mechanism of renal dysfunction in these patients and that venous congestion may play a role. An increase in central venous pressure causes a decrease in perfusion pressure across the glomeruli leading to worsening renal function [19]. In addition, these findings could implicate a role for atrial natriuretic peptides (ANP). Given that atrial stretch and increased pressure could increase ANP levels, it is surprising that volume balance is not maintained. Resistance of the kidney to the effects of ANP, the overwhelming effects of other reflex mechanisms through RAAS and the sympathetic nervous system can render the effects of ANP on the kidney less than optimal. It is interesting to consider whether the lack of effect of ANP on the kidney is a marker of severe cardiorenal syndrome type 2 or important in the pathophysiology of type 2 .

\section{Type 3: AKI}

In the acute renal-cardiac setting, AKI can lead to cardiac dysfunction by multiple pathways. An acute decrease in GFR can lead to flash pulmonary edema, volume congestion, and increased preload. The inability to balance electrolytes can lead to cardiac arrhythmias. With these complications, the key in this clinical setting is early recognition and management. Research for novel biomarkers in early detection of kidney injury has been promising. Neutrophil gelatinase-associated lipocalin (NGAL) is a protein that is released in response to renal injury. Mouse models have shown an increase in protein expression even in mild renal ischemia. The onset of serum NGAL elevation in mice occurred within hours of the ischemic event [20]. This has translated to human studies, one of which compared NGAL to SCr in 71 cardiac surgery patients monitored for AKI after surgery. In 20 patients that developed acute renal injury, urinary NGAL concentrations were increased just $2 \mathrm{~h}$ after bypass surgery versus 1-3 days when measuring SCr alone [21]. Therefore, NGAL may represent an early sensitive test to detect AKI.

Cystatin $\mathrm{C}$ is a cysteine proteinase that is found in nucleated cells and has been studied as a marker for GFR. In the clinical setting, widespread use of cystatin $\mathrm{C}$ is not common, but studies have shown its potential utility. In acute renal failure patients, cystatin $\mathrm{C}$ was increased on average 1.5-2 days earlier than SCr [22]. This result was also confirmed in a meta-analysis by Dharnidharka et al. [23] showing serum cystatin $\mathrm{C}$ is a better marker for GFR than creatinine. Other markers such as kidney injury molecule- 1 and interleukin-18 are still under investigation [2]. These all indicate potential for early detection of AKI, though large randomized trials are still needed before they are put into clinical practice.

Type 4: CKD

According to the Third National Health and Nutrition Examination Survey (NHANES III), the prevalence of CKD in the United States is approximately $11 \%$, which translates into about 19 million Americans [24]. Among these patients, cardiovascular disease is a major cause of mortality. In a meta-analysis of non-dialysis-dependent CKD patients, cardiovascular etiologies accounted for $58 \%$ of the deaths in the thirteen studies that reported cardiovascular and all-cause mortalities [25]. In another study, investigators sampled the United States Medicare population between 1998 and 1999 and found that in non- 


\section{CardioRenal \\ Medicine}

\begin{tabular}{l|l}
\hline Cardiorenal Med 2011;1:13-22 \\
\hline $\begin{array}{l}\text { DOI: 10.1159/000322820 } \\
\text { Published online: January 17, } 2011\end{array}$ & $\begin{array}{l}\text { @ 2011 S. Karger AG, Basel } \\
\text { www.karger.com/crm }\end{array}$ \\
\hline
\end{tabular}

Chan et al.: Clinical Aspects of the Cardiorenal Syndrome

diabetics with CKD, the incidence rate of developing congestive heart failure over 1 year was $30.7 \%$ [26].

The United States Renal Data System (USRDS) database is an annual publication related to statistics in those with severe and end-stage renal disease. These data shed light on the impact of cardiovascular disease on CKD. According to the USRDS, patients with CKD stage 3-5 who develop an acute myocardial infarction have mortality rates reaching $51 \%$ at 12 months. Even if patients survive the initial event, the re-hospitalization rate is about $70 \%$ in the 12 months following an acute myocardial infarction [27]. Compliance to treatment with $\beta$-blockers and angiotensin-converting enzyme inhibitors in CKD patients is about 46 and $44 \%$, respectively. The use of both agents concurrently amounts to $28 \%$ [27]. This rich data set provides invaluable information since many clinical studies exclude patients with high SCr, which limits the amount of information available in this population.

The high mortality risk in CKD patients is multifactorial, but one of the major concerns is response to PCI and CIN. In these high-risk patients, there is a trend towards conservative management, but evidence favors aggressive treatment in these cases. In an observational study, 40,374 patients who underwent coronary angiography were divided into dialysis- and non-dialysis-dependent kidney disease and control groups. The results showed that those who had treatment with either coronary artery bypass grafting (CABG) or PCI had a higher survival rate compared to those with no revascularization, especially in the dialysis group [28]. This survival advantage of revascularization has been validated in other studies as well.

Comparing PCI to CABG, multiple studies showed a benefit for CABG as the mode for revascularization. Ashrith et al. [29] published a retrospective analysis of 812 patients with $\mathrm{CKD}$ and found that in the non-dialysis-dependent patients, CABG led to better survival than PCI with drug-eluting stents. However, this result was not without comorbidity in that CABG patients had a greater risk of requiring dialysis post-operatively compared to PCI patients (4.2 vs. $1.5 \%$, respectively). In patients already on dialysis, CABG also proved to result in better outcomes. Sunagawa et al. [30] evaluated CABG versus PCI with drug-eluting stents in this population and showed that the 2-year survival was better in the CABG group than in the PCI group (84 vs. $67.6 \%$, respectively). The superiority in the CABG group in these studies may be related to complications from repeat revascularization in the PCI group or stent thrombosis. Though revascularization seems to have better outcomes, the overall mortality rate of patients with CKD is still high compared to a normal population. A large, randomized, clinical trial comparing the superiority of either revascularization method has yet to be done in this population.

\section{Type 5: Systemic Dysfunction}

This final subtype incorporates the secondary causes of the cardiorenal syndrome. Systemic illnesses such as diabetes, hypertension, amyloidosis, and lupus erythematosus are all examples of diseases that can impact both the cardiac and the renal system. Another important systemic illness is sepsis in the critically ill patient. In this setting, the increased production of tumor necrosis factor may play a role in reducing myocardial function [2]. This can lead to renal dysfunction secondary to poor renal perfusion similar to the type 1 cardiorenal syndrome described previously. Another consideration is the increase in sympathetic stimulation that leads to the down-regulation of $\beta$-adrenergic receptors that can lead to a decreased cardiac output [19]. The clinical goal in this setting is treatment of the underlying systemic disease. 


\section{CardioRenal \\ Medicine}

\begin{tabular}{l|l}
\hline \multicolumn{2}{l}{ Cardiorenal Med 2011;1:13-22 } \\
\hline DOI: $10.1159 / 000322820$ \\
Published online: January 17, 2011 & $\begin{array}{l}\text { @ } 2011 \text { S. Karger AG, Basel } \\
\text { www.karger.com/crm }\end{array}$ \\
\hline
\end{tabular}

Chan et al.: Clinical Aspects of the Cardiorenal Syndrome

\section{Management}

The management of patients with the cardiorenal syndrome is often complex and challenging. From a cardiac perspective, the treatment of heart failure often relies on large doses of diuretics and afterload reduction in order to optimize preload and afterload. As a result of volume depletion, renal function worsens. Conversely, treatment with volume to preserve renal function leads to pulmonary and systemic congestion and worsening heart failure. This has led clinicians to evolve therapies to find this delicate balance between these two interconnected systems.

\section{Loop Diuretics}

Loop diuretics are the standard therapy in the treatment of acute heart failure exacerbation. The aggressive use of loop diuretics, though, can initiate a cascade of events leading to worsening renal function. Volume depletion with or without associated hypotension leads to RAAS activation causing sodium retention and further worsening of renal function. Close attention should be paid to hemodynamic parameters, especially renal perfusion pressure, weight loss, and edema, during treatment.

Another important concept in managing patients with loop diuretics is diuretic resistance. The 'braking phenomenon' is described as avid sodium retention in the distal tubules that occurs usually after a single dose of diuretics. The mechanism behind this phenomenon is not clearly understood, but may be secondary to hypertrophy of distal tubules [31]. Regardless of the cause, this phenomenon leads to a poorer response to subsequent dosing of diuretics ultimately leading to an inability to decrease intravascular congestion. In these cases, continuous infusion of furosemide may be more effective than bolus dosing [32]. The concomitant use of thiazides may also improve diuresis in this setting by blocking sodium reabsorption in the distal tubules [33].

\section{Nesiritide}

Nesiritide, a recombinant human B-type natriuretic peptide, is a vasodilator with mild diuretic effects. It acts by increasing cyclic GMP leading to smooth muscle relaxation, thereby reducing cardiac filling pressures. While using nesiritide is theoretically promising, its clinical role in heart failure treatment is still in question. Colucci et al. [34] demonstrated there may be a short-term role of nesiritide in patients admitted with decompensated heart failure. In the study, a two-arm design was employed to compare pulmonary capillary wedge pressure and clinical symptoms. Nesiritide (at doses of 0.015 and $0.03 \mu \mathrm{g} / \mathrm{kg} / \mathrm{min}$ ) decreased pulmonary capillary wedge pressure by $9.6 \mathrm{~mm} \mathrm{Hg}$ at the higher dose. Patients also reported symptom reduction in dyspnea by $57 \%$ [34].

Despite the possible role of nesiritide in treating symptoms of heart failure, a meta-analysis showed that regular- and low-dose nesiritide $(<0.03$ and $<0.015 \mu \mathrm{g} / \mathrm{kg} / \mathrm{min}$, respectively) may significantly increase the risk of worsening renal function in patients with acutely decompensated heart failure. The patients receiving low doses of nesiritide were compared to control patients where therapy consisted of diuretics and other vasodilators. The data were pooled from five randomized studies that included 1,269 patients. The frequency of worsening renal function, defined as an increase in $\mathrm{SCr}>0.5 \mathrm{mg} / \mathrm{dl}$ at any time during patient admission, was $21 \%$ in patients treated with nesiritide compared to $15 \%$ in the control group [35]. In this meta-analysis, there was no difference between the nesiritide and control groups in terms of patients requiring dialysis. Based on these data, nesiritide may improve shortterm symptoms, but side effects such as worsening renal function are still a concern. The potential use of nesiritide in treatment is currently still under investigation. The forthcoming Acute Study of Clinical Effectiveness of Nesiritide in Decompensated Heart Failure 


\section{CardioRenal \\ Medicine}

\begin{tabular}{l|l}
\hline Cardiorenal Med 2011;1:13-22 \\
\hline DOI: 10.1159/000322820 & $\begin{array}{l}\text { @ 2011 S. Karger AG, Basel } \\
\text { www.karger.com/crm }\end{array}$ \\
\hline Published online: January 17, 2011 &
\end{tabular}

Chan et al.: Clinical Aspects of the Cardiorenal Syndrome

(ASCEND-HF) is an outcome trial that may elucidate its role. Endpoints in that trial include all-cause mortality, re-hospitalization rates for heart failure, as well as worsening renal function [36].

\section{Ultrafiltration}

Patients with cardiorenal syndrome may still have significant volume overload and venous (pulmonary and systemic) congestion despite being treated with diuretics. Independent of whether this is secondary to diuretic resistance or worsening renal function, other viable options for fluid removal such as ultrafiltration are considered. The Ultrafiltration versus Intravenous Diuretics for Patients Hospitalized for Acute Decompensated Heart Failure (UNLOAD) trial, a prospective, randomized, multicenter trial, compared ultrafiltration to standard diuretic therapy. Two hundred patients were randomized to ultrafiltration or intravenous diuretics, with the diuretic dose in the protocol set to the level of at least two times the total dose patients were taking prior to hospitalization. The primary endpoints included reduction in weight and dyspnea symptoms of patients on admission. After 90 days, the ultrafiltration group showed less patient re-hospitalizations and a greater net reduction in fluid loss during hospitalization (4.6 compared to 3.3 liters in the controls). There were no significant differences between the two treatment groups in SCr and dyspnea scores [37]. This trial showed the potential use of ultrafiltration as a viable treatment option in patients with the cardiorenal syndrome, but long-term outcome has yet to be determined. Currently, the Cardiorenal Rescue Study in Acute Decompensated Heart Failure (CARRESS) designed to study standard medical drug therapy versus ultrafiltration is underway. Its primary outcome measures are changes in SCr and weight. This study is currently recruiting patients [38].

\section{Future Treatment Prospects}

\section{Tolvaptan (Vasopressin Antagonist)}

Arginine vasopressin (AVP), or anti-diuretic hormone, is secreted by the posterior pituitary gland in response to changes in osmotic concentrations in the extracellular fluid. It acts by binding to three AVP receptor subtypes. The two vasopressin receptors important in the pathogenesis and worsening of heart failure include $V_{\text {la }}$ receptors (found on smooth muscle cells), which cause arterial vasoconstriction in response to AVP, and $V_{2}$ receptors (found in the renal collecting tubules), which result in an increased free water absorption in response to AVP [31]. For these reasons, investigators looked into inhibiting $\mathrm{V}_{2}$ receptors to prevent reabsorption of fluid leading to worsening vascular congestion. The most clinically studied compound to date has been tolvaptan, an oral $\mathrm{V}_{2}$ receptor antagonist.

The efficacy of tolvaptan was evaluated in multiple studies. The Effects of Tolvaptan, a Vasopressin Antagonist, in Patients Hospitalized with Worsening Heart Failure (ACTIV) trial was a randomized, double-blind, placebo-controlled study that enrolled 319 patients to receive 30,60 , or $90 \mathrm{mg}$ of tolvaptan or placebo in addition to standard therapy. Tolvaptan was continued for up to 60 days. Results showed that tolvaptan was effective in decreasing body weight $24 \mathrm{~h}$ following randomization, $-2.5 \mathrm{~kg}$ in the 90 -mg tolvaptan group versus -0.6 $\mathrm{kg}$ in the control group. It is important to note that there was no significant change in $\mathrm{SCr}$ in the tolvaptan group at the time of discharge [39].

In another study, the Effects of Oral Tolvaptan in Patients Hospitalized for Worsening Heart Failure (EVEREST) trial, 4,133 patients were randomized to receive $30 \mathrm{mg}$ of tolvaptan once daily or placebo in addition to standard therapy. The study excluded patients with SCr $>3.5 \mathrm{mg} / \mathrm{dl}$. The results showed no difference in the primary endpoints of all-cause mortality or hospitalization for heart failure. However, it did show improvement in secondary endpoints 
of dyspnea and body weight compared to standard therapy. Changes in body weight were -1.76 $\mathrm{kg}$ in the tolvaptan group and $-0.97 \mathrm{~kg}$ in the placebo group. Serum sodium levels, a known predictor of an adverse outcome, were significantly increased by almost $6 \mathrm{mEq} / \mathrm{l}$ from baseline by the time of discharge in the tolvaptan group. The 9.9-month follow-up duration in the EVEREST trial was greater than the follow-up in the ACTIV trial. There were no differences in mortality between the tolvaptan and placebo groups after 9 months of treatment and follow-up [40]. Therefore, the EVEREST study showed improvement in symptoms of edema and dyspnea with no effects on mortality at nearly 10 months. These two studies showed that tolvaptan is an effective therapeutic option in the acute treatment of patients with heart failure. Further studies are needed to evaluate whether long-term mortality benefits exist.

\section{Adenosine $A_{1}$ Receptor Antagonists}

There are four different subtypes of adenosine receptors. $A_{1}$ receptor activation causes renal afferent arteriolar constriction leading to decreased renal blood flow and increased sodium reabsorption. It has also been suggested that $\mathrm{A}_{1}$ receptors directly affect cardiac remodeling by promoting cardiac fibrosis [41]. This led to the development of selective $\mathrm{A}_{1}$ receptor antagonists such as BG9719 and KW-3902 [31]. To date, both compounds show promise in preserving renal function in conjunction with standard diuretic therapy. More definitive studies are currently in progress.

\section{Conclusion}

The definition and pathophysiological understanding of the cardiorenal syndrome continue to evolve. Markers for AKI can potentially detect renal injury at an early stage and therefore result in earlier treatment initiation. Management of the cardiorenal syndrome will advance as more data from clinical trials such as ASCEND-HF and CARRESS become available. From a cardiologist's perspective, one thing remains clear. The management of the cardiorenal syndrome involves a multidisciplinary approach between cardiologists, nephrologists, and intensivists. Treatment needs to focus on the co-dependent relationship between these two vital organ systems.

\section{Disclosure Statement}

There are no conflicts of interest.

\section{References}

1 Guyton AC, Hall JE: Textbook of Medical Physiology. New York, Saunders, 2000.

-2 Ronco C, Haapio M, House AA, Anavekar N, Bellomo R: Cardiorenal syndrome. J Am Coll Cardiol 2008;52:15271539.

3 Lloyd-Jones D, Adams RJ, Brown TM, Carnethon M, Dai S, De Simone G, Ferguson TB, Ford E, Furie K, Gillespie C, Go A, Greenlund K, Haase N, Hailpern S, Ho PM, Howard V, Kissela B, Kittner S, Lackland D, Lisabeth L, Marelli A, McDermott MM, Meigs J, Mozaffarian D, Mussolino M, Nichol G, Roger VL, Rosamond W, Sacco R, Sorlie P, Stafford R, Thom T, Wasserthiel-Smoller S, Wong ND, Wylie-Rosett J, American Heart Association Statistics Committee and Stroke Statistics Subcommittee: Executive summary: heart disease and stroke statistics - 2010 update: a report from the American Heart Association. Circulation 2010;121:948-954.

-4 Adams KF Jr, Fonarow GC, Emerman CL, LeJemtel TH, Costanzo MR, Abraham WT, Berkowitz RL, Galvao M, Horton DP, ADHERE Scientific Advisory Committee and Investigators: Characteristics and outcomes of patients hospitalized for heart failure in the United States: rationale, design, and preliminary observations from the first 100,000 cases in the Acute Decompensated Heart Failure National Registry (ADHERE). Am Heart J 2005;149:209-216. 


\section{CardioRenal Medicine}

\begin{tabular}{l|l}
\hline Cardiorenal Med 2011;1:13-22 \\
\hline DOI: 10.1159/000322820 & $\begin{array}{l}\text { @) 2011 S. Karger AG, Basel } \\
\text { www.karger.com/crm }\end{array}$ \\
\hline Published online: January 17, 2011 &
\end{tabular}

Chan et al.: Clinical Aspects of the Cardiorenal Syndrome

5 Fonarow GC, Adams KF, Abraham WT, Yancy CW, Boscardin WJ: Risk stratification for in-hospital mortality in acutely decompensated heart failure: classification and regression tree analysis. JAMA 2005;293:572-580.

6 Braunwald E, Libby P, Bonow R, Mann DL, Zipes DP: Braunwald's Heart Disease. Philadelphia, Saunders, 2008.

7 Ronco C, House AA, Haapio M: Cardiorenal syndrome: refining the definition of a complex symbiosis gone wrong. Intensive Care Med 2008;34:957-962.

$>8$ Benigni A, Remuzzi G: Endothelin antagonists. Lancet 1999;353:133-138.

9 Weisbord SD, Palevsky PM: Radiocontrast-induced acute renal failure. J Intensive Care Med 2005;20:63-75.

10 Sandler CM: Contrast-agent-induced acute renal dysfunction - is iodixanol the answer? N Engl J Med 2003;348:551553.

11 Rudnick MR, Goldfarb S, Wexler L, Ludbrook PA, Murphy MJ, Halpern EF, Hill JA, Winniford M, Cohen MB, VanFossen DB: Nephrotoxicity of ionic and nonionic contrast media in 1196 patients: a randomized trial. The Iohexol Cooperative Study. Kidney Int 1995;47:254-261.

-12 Aspelin P, Aubry P, Fransson SG, Strasser R, Willenbrock R, Berg KJ, Nephrotoxicity in High-Risk Patients Study of Iso-Osmolar and Low-Osmolar Non-Ionic Contrast Media Study Investigators: Nephrotoxic effects in high-risk patients undergoing angiography. N Engl J Med 2003;348:491-499.

13 Mehran R, Aymong ED, Nikolsky E, Lasic Z, Iakovou I, Fahy M, Mintz GS, Lansky AJ, Moses JW, Stone GW, Leon $\mathrm{MB}$, Dangas G: A simple risk score for prediction of contrast-induced nephropathy after percutaneous coronary intervention: development and initial validation. J Am Coll Cardiol 2004;44:1393-1399.

- 14 Marenzi G, Assanelli E, Campodonico J, De Metrio M, Lauri G, Marana I, Moltrasio M, Rubino M, Veglia F, Montorsi P, Bartorelli AL: Acute kidney injury in ST-segment elevation acute myocardial infarction complicated by cardiogenic shock at admission. Crit Care Med 2010;38:438-444.

15 Koreny M, Karth GD, Geppert A, Neunteufl T, Priglinger U, Heinz G, Siostrzonek P: Prognosis of patients who develop acute renal failure during the first 24 hours of cardiogenic shock after myocardial infarction. Am J Med 2002; 112:115-119.

16 Binanay C, Califf RM, Hasselblad V, O’Connor CM, Shah MR, Sopko G, Stevenson LW, Francis GS, Leier CV, Miller LW, ESCAPE Investigators and ESCAPE Study Coordinators: Evaluation study of congestive heart failure and pulmonary artery catheterization effectiveness: the ESCAPE trial. JAMA 2005;294:1625-1633.

17 Nohria A, Hasselblad V, Stebbins A, Pauly DF, Fonarow GC, Shah M, Yancy CW, Califf RM, Stevenson LW, Hill JA: Cardiorenal interactions: insights from the ESCAPE trial. J Am Coll Cardiol 2008;51:1268-1274.

-18 Mullens W, Abrahams Z, Francis GS, Sokos G, Taylor DO, Starling RC, Young JB, Tang WH: Importance of venous congestion for worsening of renal function in advanced decompensated heart failure. J Am Coll Cardiol 2009;53: 589-596.

19 Bock JS, Gottlieb SS: Cardiorenal syndrome: new perspectives. Circulation 2010;121:2592-2600.

20 Mishra J, Ma Q, Prada A, Mitsnefes M, Zahedi K, Yang J, Barasch J, Devarajan P: Identification of neutrophil gelatinase-associated lipocalin as a novel early urinary biomarker for ischemic renal injury. J Am Soc Nephrol 2003;14: 2534-2543.

21 Mishra J, Dent C, Tarabishi R, Mitsnefes MM, Ma Q, Kelly C, Ruff SM, Zahedi K, Shao M, Bean J, Mori K, Barasch J, Devarajan P: Neutrophil gelatinase-associated lipocalin (NGAL) as a biomarker for acute renal injury after cardiac surgery. Lancet 2005;365:1231-1238.

22 Herget-Rosenthal S, Marggraf G, Hüsing J, Göring F, Pietruck F, Janssen O, Philipp T, Kribben A: Early detection of acute renal failure by serum cystatin C. Kidney Int 2004;66:1115-1122.

23 Dharnidharka VR, Kwon C, Stevens G: Serum cystatin C is superior to serum creatinine as a marker of kidney function: a meta-analysis. Am J Kidney Dis 2002;40:221-226.

24 Coresh J, Astor BC, Greene T, Eknoyan G, Levey AS: Prevalence of chronic kidney disease and decreased kidney function in the adult US population: Third National Health and Nutrition Examination Survey. Am J Kidney Dis 2003;41: $1-12$.

25 Tonelli M, Wiebe N, Culleton B, House A, Rabbat C, Fok M, McAlister F, Garg AX: Chronic kidney disease and mortality risk: a systematic review. J Am Soc Nephrol 2006;17:2034-2047.

26 Foley RN, Murray AM, Li S, Herzog CA, McBean AM, Eggers PW, Collins AJ: Chronic kidney disease and the risk for cardiovascular disease, renal replacement, and death in the United States Medicare population, 1998 to 1999. J Am Soc Nephrol 2005;16:489-495.

27 Annual Data Report. http://www.usrds.org/adr.htm (accessed October 20, 2010).

-28 Hemmelgarn BR, Southern D, Culleton BF, Mitchell LB, Knudtson ML, Ghali WA, Alberta Provincial Project for Outcomes Assessment in Coronary Heart Disease (APPROACH) Investigators: Survival after coronary revascularization among patients with kidney disease. Circulation 2004;110:1890-1895.

29 Ashrith G, Lee V, Elayda MA, Reul RM, Wilson JM: Short- and long-term outcomes of coronary artery bypass grafting or drug-eluting stent implantation for multivessel coronary artery disease in patients with chronic kidney disease. Am J Cardiol 2010;106:348-353.

-30 Sunagawa G, Komiya T, Tamura N, Sakaguchi G, Kobayashi T, Murashita T: Coronary artery bypass surgery is superior to percutaneous coronary intervention with drug-eluting stents for patients with chronic renal failure on hemodialysis. Ann Thorac Surg 2010;89:1896-1900, discussion 1900.

- 31 Liang KV, Williams AW, Greene EL, Redfield MM: Acute decompensated heart failure and the cardiorenal syndrome. Crit Care Med 2008;36(suppl 1):S75-S88. 


\section{CardioRenal Medicine}

\begin{tabular}{l|l}
\hline Cardiorenal Med 2011;1:13-22 \\
\hline $\begin{array}{l}\text { DOl: 10.1159/000322820 } \\
\text { Published online: January 17, } 2011\end{array}$ & $\begin{array}{l}\text { ○ 2011 S. Karger AG, Basel } \\
\text { www.karger.com/crm }\end{array}$ \\
\hline
\end{tabular}

Chan et al.: Clinical Aspects of the Cardiorenal Syndrome

32 Francis G: Acute decompensated heart failure: the cardiorenal syndrome. Cleve Clin J Med 2006;73(suppl 2):S8-S13, discussion S30-S33.

33 Liu PP: Cardiorenal syndrome in heart failure: a cardiologist's perspective. Can J Cardiol 2008;24(suppl B):25B-29B.

-34 Colucci WS, Elkayam U, Horton DP, Abraham WT, Bourge RC, Johnson AD, Wagoner LE, Givertz MM, Liang CS, Neibaur M, Haught WH, LeJemtel TH: Intravenous nesiritide, a natriuretic peptide, in the treatment of decompensated congestive heart failure. Nesiritide Study Group. N Engl J Med 2000;343:246-253.

-35 Sackner-Bernstein JD, Skopicki HA, Aaronson KD: Risk of worsening renal function with nesiritide in patients with acutely decompensated heart failure. Circulation 2005;111:1487-1491.

-36 Hernandez AF, O’Connor CM, Starling RC, Reist CJ, Armstrong PW, Dickstein K, Lorenz TJ, Gibler WB, Hasselblad V, Komajda M, Massie B, McMurray JJ, Nieminen M, Rouleau JL, Swedberg K, Califf RM: Rationale and design of the Acute Study of Clinical Effectiveness of Nesiritide in Decompensated Heart Failure Trial (ASCEND-HF). Am Heart J 2009;157:271-277.

37 Costanzo MR, Guglin ME, Saltzberg MT, Jessup ML, Bart BA, Teerlink JR, Jaski BE, Fang JC, Feller ED, Haas GJ, Anderson AS, Schollmeyer MP, Sobotka PA for the UNLOAD Trial Investigators: Ultrafiltration versus intravenous diuretics for patients hospitalized for acute decompensated heart failure. J Am Coll Cardiol 2007;49:675-683.

38 Effectiveness of Ultrafiltration in Treating People with Acute Decompensated Heart Failure and Cardiorenal Syndrome (the CARRESS Study). http://clinicaltrials.gov/ct2/show/NCT00608491 (accessed October 19, 2010).

-39 Gheorghiade M, Gattis WA, O’Connor CM, Adams KF Jr, Elkayam U, Barbagelata A, Ghali JK, Benza RL, McGrew FA, Klapholz M, Ouyang J, Orlandi C, Acute and Chronic Therapeutic Impact of a Vasopressin Antagonist in Congestive Heart Failure (ACTIV in CHF) Investigators: Effects of tolvaptan, a vasopressin antagonist, in patients hospitalized with worsening heart failure: a randomized controlled trial. JAMA 2004;291:1963-1971.

40 Konstam MA, Gheorghiade M, Burnett JC Jr, Grinfeld L, Maggioni AP, Swedberg K, Udelson JE, Zannad F, Cook T, Ouyang J, Zimmer C, Orlandi C, Efficacy of Vasopressin Antagonism in Heart Failure Outcome Study with Tolvaptan (EVEREST) Investigators: Effects of oral tolvaptan in patients hospitalized for worsening heart failure: the EVEREST Outcome Trial. JAMA 2007;297:1319-1331.

41 Gottlieb SS: Adenosine A1 antagonists and the cardiorenal syndrome. Curr Heart Fail Rep 2008;5:105-109. 